\title{
Analysis of von Willebrand factor multimers using a commercially available enhanced chemiluminescence kit
}

\author{
A M Cumming, R T Wensley
}

\begin{abstract}
Aims-To develop a rapid, sensitive, and safe method for the analysis of von Willebrand factor (vWf) multimers in plasma or platelet lysates.

Method-Analysis of $\mathrm{vWf}$ multimers was carried out by sodium dodecyl sulphateagarose discontinuous gel electrophoresis followed by protein transfer to nitrocellulose membranes by western blotting. Blots were probed using horseradish peroxidase (HRP) conjugated rabbit anti-vWf; visualisation of $v W f$ multimers was achieved using a commercially available enhanced chemiLuminescence (ECL) kit for detecting HRP labelled antibodies on western blots.
\end{abstract}

Results-Electrophoretic transfer of vWf multimers to nitrocellulose membranes, including the higher molecular weight forms, was achieved satisfactorily and there was good resolution of individual multimer bands and of the triplet subband structure. Type II vWD variants were readily identifiable. The use of ECL conferred a high degree of sensitivity to the method and the end result on autoradiography film provided a permanent record which did not fade and which was suitable for scanning densitometry.

Conclusion-The method for vWf multimer analysis described here is sensitive, simple to carry out, uses minimal amounts of reagents, produces results within 48 hours, and does not require the use of potentially hazardous radioactive materials or carcinogenic enzyme substrates.

(F Clin Pathol 1993;46:470-473)

Von Willebrand factor (vWf) is a large multimeric glycoprotein that has essential roles in the adhesion of platelets to subendothelium in primary haemostasis and as a carrier protein for procoagulant factor VIII. It is present in plasma as a range of multimers, assembled from the 250 kilodalton monomeric subunit, with molecular weights of up to $20 \times 10^{6}$ daltons. The analysis of vWf multimers is necessary for the classification of von Willebrand disease (vWD), an autosomally inherited bleeding disorder resulting from quantitative (vWD types I and III) or qualitative (vWD type II variants) abnormalities of vWf. ${ }^{1}$ The most common of the inherited bleeding disorders, vWD has a reported incidence in the population as high as $1 \%$ or more. $^{23}$

Several different methods have been described for the analysis of $\mathrm{vWf}$ multimers in plasma or in platelet lysates. Methods using ${ }^{125}$ I-labelled anti-vWf ${ }^{4-8}$ are sensitive and autoradiography provides a permanent record for future reference or for carrying out scanning densitometry. The use of radioisotopes, however, is potentially hazardous and many laboratories do not have the appropriate facilities. These methods are also time consuming and expensive. Other methods where enzyme-labelled antibodies are used as an alternative to radiolabelled antibodies ${ }^{9-14}$ have the advantages of being more rapid, more economical, and potentially less hazardous to perform. Disadvantages are that some enzyme substrates may be carcinogenic, and the end result is usually unstable, often fragile (for example on nitrocellulose membranes), and not readily subjected to scanning densitometry.

We describe a sensitive, non-radioactive method for the analysis of vWf multimers which can be carried out within 48 hours and which, by the use of enhanced chemiLuminescence (ECL) technology, provides a permanent record which does not fade and which is suitable for scanning densitometry.

\section{Methods}

ELECTROPHORESIS

Blood was collected on to 1 in 10 volume $0.106 \mathrm{M}$ trisodium citrate. Plasma was separated by centrifugation at $2000 \times g$ for 15 minutes and stored at $-30^{\circ} \mathrm{C}$ until analysis. Analysis of vWf multimers was carried out by SDS-agarose discontinuous gel electrophoresis, ${ }^{6}$ using $1.5 \%$ agarose for high resolution gels and $1.0 \%$ agarose for low resolution gels. Low gelling temperature agarose, type VII (Sigma Chemical Company, Poole, Dorset), was used throughout and electrophoresis was carried out using an LKB Multiphor 2117 system (Pharmacia LKB Biotechnology, Uppsala, Sweden).

Resolving gels were prepared by heating agarose to $100^{\circ} \mathrm{C}$ in $0.5 \mathrm{M}$ TRIS (pH 8.8), $0 \cdot 1 \%$ SDS. After cooling to $60^{\circ} \mathrm{C}$ the gel was poured between two glass plates separated by a $1 \mathrm{~mm}$ thick U-shaped former to give gel dimensions of $20 \times 10.5 \mathrm{~cm}$. Gels were supported on Gelbond (Pharmacia LKB Biotechnology). After polymerisation a $2 \mathrm{~cm}$ strip was removed from the top of the 
resolving gel and the stacking gel $(0 \cdot 8 \%$ agarose in $0.125 \mathrm{M}$ TRIS ( $\mathrm{pH} 6.8$ ), SDS $0 \cdot 1 \%$ ) was added at $60^{\circ} \mathrm{C}$. Subsequent to its polymerisation, 10 sample wells $(8 \times 2 \mathrm{~mm})$ were cut into the stacking gel $8 \mathrm{~mm}$ from its interface with the resolving gel.

Plasma or platelet lysate ${ }^{15}$ samples were

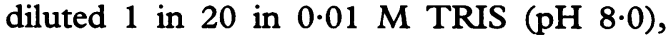
$1 \mathrm{mM} \mathrm{Na}{ }_{2}$ EDTA, 2\% SDS and incubated at $60^{\circ} \mathrm{C}$ for 30 minutes. A $1 \%$ solution of bromophenol blue $(5 \mu \mathrm{l})$ was added to each diluted sample for tracking purposes. The diluted samples $(20 \mu \mathrm{l})$ were transferred into the sample wells and electrophoresis was carried out at a constant current of $30 \mathrm{~mA}$, with cooling to $10^{\circ} \mathrm{C}$ and using wicks of four layers of $3 \mathrm{M}$ chromatography paper (Whatman, Maidstone, Kent). The electrophoresis tank buffer was $0.05 \mathrm{M}$ TRIS, $0.384 \mathrm{M}$ glycine, $0 \cdot 1 \%$ SDS (pH 8.35).

When the tracking dye front approached the interface of the stacking gel with the resolving gel (30 to 40 minutes) the sample wells were filled with stacking gel. Electrophoresis was then continued at a constant current of $9 \mathrm{~mA}$ for about 16 hours until the tracking dye had migrated to the anodal end of the resolving gel.

\section{WESTERN BLOTTING}

After electrophoresis the gel was equilibrated for 30 minutes in western blotting transfer buffer (25 mM TRIS, $192 \mathrm{mM}$ glycine, $20 \%$ methanol, $0 \cdot 1 \%$ SDS, $\mathrm{pH} 8 \cdot 3$ ). The gel was separated from the Gelbond support by passing a nylon thread between the gel and the Gelbond and then inverting the gel on to a pre-wetted nitrocellulose membrane. Electroblotting was carried out for six hours at $0.3 \mathrm{~A}$ and $8^{\circ} \mathrm{C}$ using a Transphor electroblotting unit (Pharmacia LKB Biotechnology) according to the manufacturer's instructions.

\section{IMMUNOENZYMATIC DETECTION}

Subsequent to western blotting the nitrocellulose membrane was rinsed in $10 \mathrm{mM}$ phosphate buffered saline (PBS), $\mathrm{pH} \mathrm{7 \cdot 4}$. It was then blocked using $100 \mathrm{ml}$ of $5 \%$ low-fat dried milk in PBS, $0.1 \%$ Tween 20 , in a shaking water bath at $37^{\circ} \mathrm{C}$ for one hour. Following rinsing with PBS the membrane was placed inside a $200 \mathrm{ml}$ screw-capped cylindrical container (Sterilin Ltd, Hounslow, Middlesex) with the protein side facing inwards. A 1 in 200 dilution of horseradish peroxidase (HRP) conjugated rabbit anti-vWf (Dako Ltd, High Wycombe, Bucks) in $10 \mathrm{ml}$ PBS $/ 1 \%$ low-fat dried milk was added to the container. The membrane was probed overnight at room temperature using roller mixing as described by Thomas et al. ${ }^{16}$ The blot was rinsed twice with PBS/0.1\% Tween 20 and then washed once for 15 minutes and four times for 5 minutes each using $100 \mathrm{ml}$ volumes of $\mathrm{PBS} / 0 \cdot 1 \%$ Tween 20 with roller mixing.

ENHANCED CHEMIIUMINESCENCE (ECL) Visualisation of $\mathrm{vWf}$ multimers was achieved by the use of an ECL kit for the detection of
HRP-labelled antibodies on western blots (Amersham International UK). The kit was used according to the manufacturer's instructions. Briefly, a mixture of equal volumes of reagents 1 and 2 was prepared and poured on to the nitrocellulose membrane. After 1 minute the blot was drained and wrapped in SaranWrap. The treated blot was placed in a film cassette and immediately exposed to autoradiography film (Hyperfilm-ECL, Amersham International). This was carried out in the dark-room using exposure times of 5 to 15 seconds. The exposed films were developed as soon as convenient.

\section{${ }^{125}$ I-AUTORADIOGRAPHY}

Electrophoresis was performed as described above and the gel was probed with ${ }^{125} \mathrm{I}$ labelled anti-vWf. ${ }^{6}$ Multimers were visualised by placing the gel in a film cassette and exposing it, at $-70^{\circ} \mathrm{C}$, to autoradiography film for 24 to 48 hours as required. The exposed film was developed immediately.

\section{Results}

An example of vWf multimer analysis using ECL visualisation is shown in figure 1. A 15 second exposure to autoradiography film was used. At least 16 main multimer bands were consistently distinguishable in normal plasma (lanes 1 and 7) and the triplet sub-band structure was well defined. The absence of the higher molecular weight multimers in type II vWD variants (lanes 3 and 4) was readily apparent using $1.5 \%$ agarose gels, and the characteristic enhancement of the triplet sub-bands, often seen in type II variants, was easily discernible. One or two faint comparatively low molecular weight multimers were often present in type III vWD plasma samples (lane 5). The distribution of multimers found in a normal platelet lysate sample can be seen in lane 6.

Figure 2 shows an example of vWf multimer analysis using ${ }^{125} \mathrm{I}$-autoradiography with 36 hours of exposure to autoradiography film. Resolution of the higher molecular weight bands was inferior to that achieved with ECL and only 11 or 12 main multimer bands were individually distinguishable in normal plasma (lanes 1 and 5). The distribution and resolution of multimers in type II vWD variants (lanes 2 and 3) were similar to those revealed by ECL. No multimer bands were visible in the type III vWD plasma sample (lane 4).

\section{Discussion}

The use of luminography for vWf multimer analysis has already been reported by Schneppenheim and colleagues, ${ }^{17}$ who described a method using individual reagents for luminography rather than a commercially available kit. These workers (and others ${ }^{10}$ ) observed incomplete electrophoretic transfer of the higher molecular weight multimers on to nitrocellulose filters, a phenomenon which may cause problems with the identification of type II vWD variants where the higher molec- 
Figure $1 \quad E C L$ visualisation of $v W f$ multimers after electrophoresis

using a $1 \cdot 5 \%$ agarose gel.

Lane 1-normal plasma

(this sample was also run

in fig 2, lanes 1 and 5);

lane 2-type I $v W D$ plasma

(vWf:Ag 0.13 IU $/ \mathrm{ml}$ );

lane 3-type ILA vWD

plasma; lane 4-type IIB

$v W D$ plasma (this sample

was also run in fig 2, lane

3); lane 5-type III vWD

plasma (vWf:Ag 0.02

IU/ml-this sample was also

run in fig 2,

lane 4); lane 6-normal

platelet lysate; lane 7 -

normal plasma.

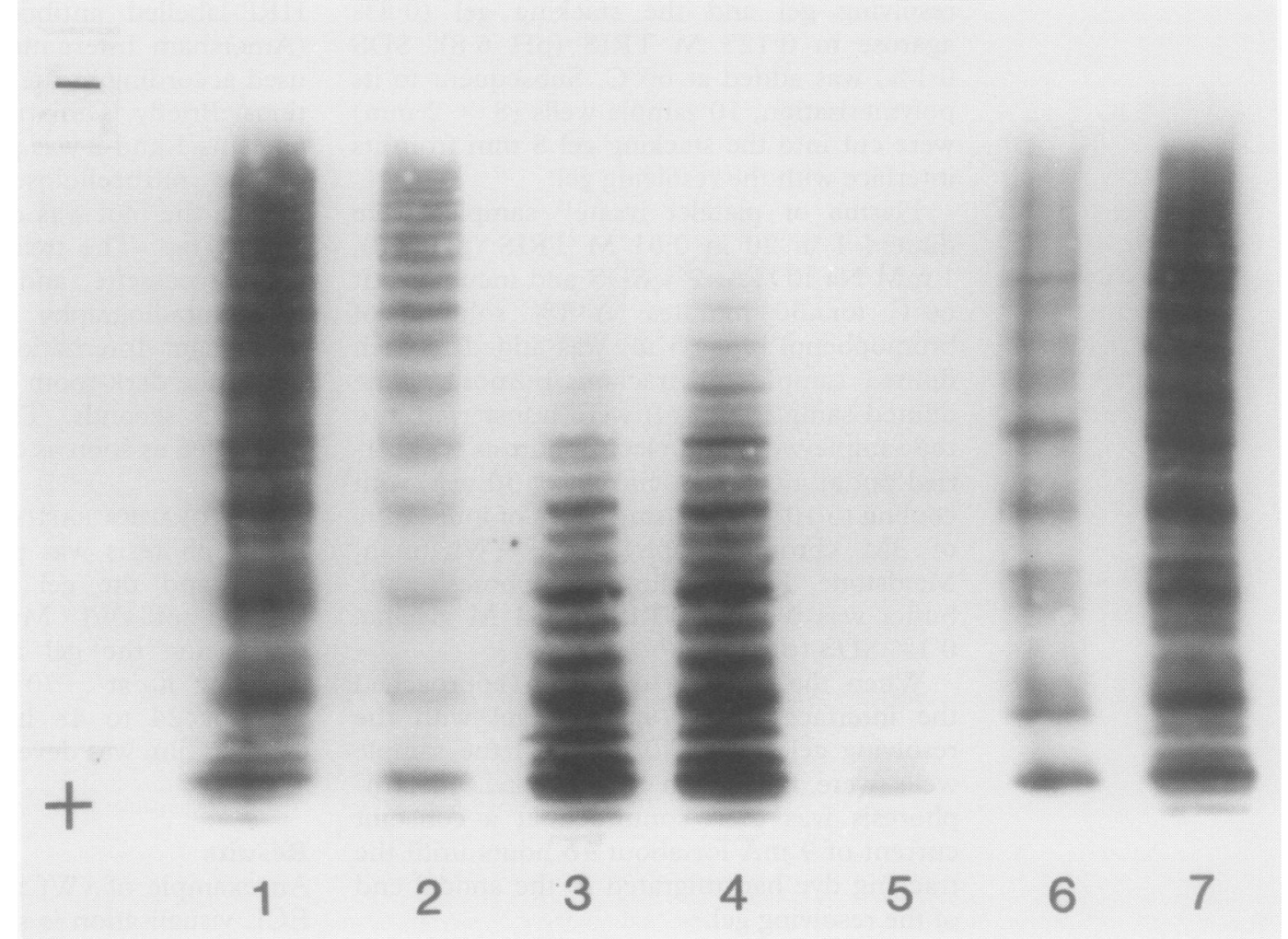

ular weight multimers are absent to varying degrees. Budde and coworkers have also described the use of ECL for visualisation of vWf multimers. ${ }^{18}$ However, these investigators found it necessary to combine ECL with the use of streptavidin and biotin technology to achieve the required sensitivity. They also reported some difficulty in transferring the

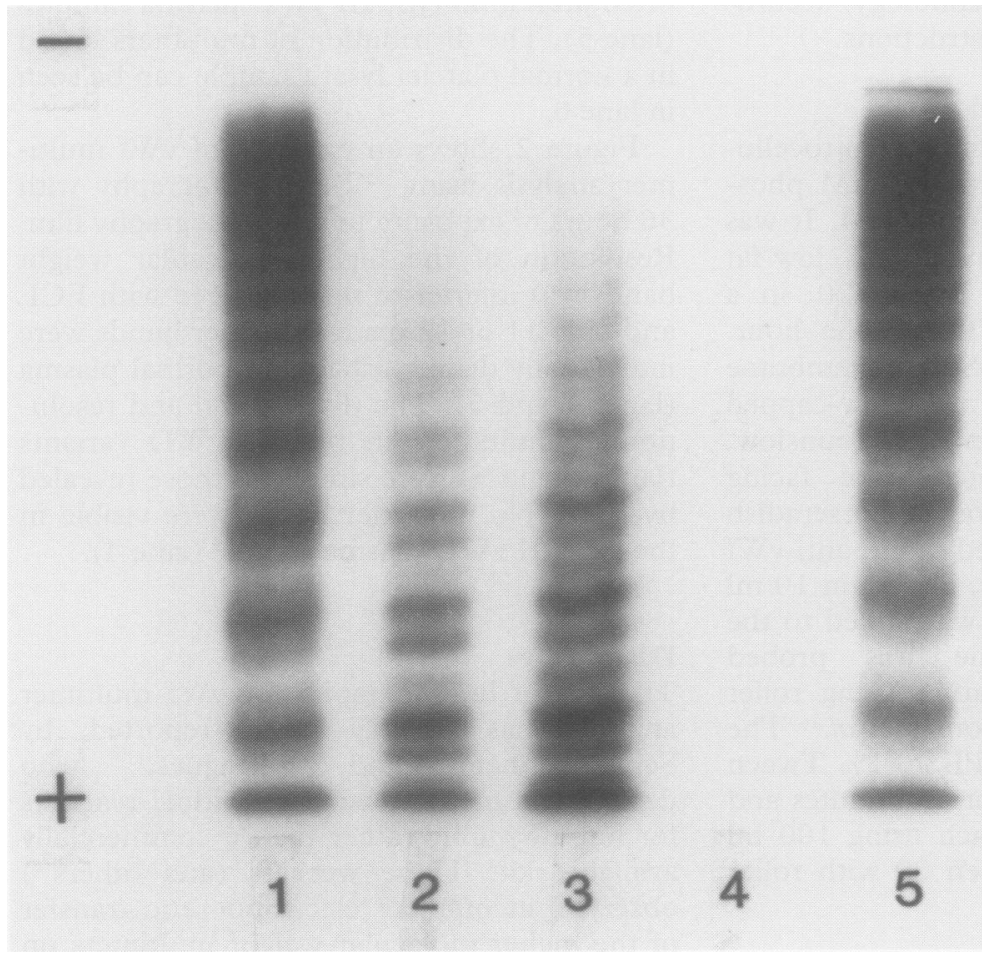

Figure 2 Visualisation of vWf multimers by ${ }^{125}$ I-autoradiography after electrophoresis using a $1 \cdot 5 \%$ agarose gel. Lane 1-normal plasma; lane 2-type IIB vWD plasma; lane 3-type IIB vWD plasma; lane 4-type III vWD plasma; lane 5-normal plasma. largest multimers from the electrophoresis gel to the nitrocellulose membrane.

Using the present method, there was no difficulty in transferring the largest multimer bands (fig 1) and results were comparable with those we have achieved previously by direct ${ }^{125}$ I-autoradiography of agarose gels (fig 2). Indeed, there was better resolution of the higher molecular weight multimers into discrete bands than we have seen with ${ }^{125} \mathrm{I}-$ autoradiography. The use of the ECL kit conferred a high degree of sensitivity on to the method and there was no need for the use of avidin and biotin reagents. For example, the multimer distribution of a plasma sample containing $0.13 \mathrm{IU} / \mathrm{ml}$ of $\mathrm{vWf}$ antigen (measured by ELISA) was easily visualised by ECL (fig 1), and the lower molecular weight multimers which were seen in type III vWD when ECL-visualisation was used (fig 1) were not apparent using ${ }^{125}$ I-autoradiography (fig 2). The latter observation suggested that ECL may in this instance be the more sensitive of these two methods.

The end result on autoradiography film provided a permanent record which did not fade and which was eminently suitable for scanning densitometry. Sensitivity was such that the time required for exposure of blots to autoradiography film was consistently within the range of 5-15 seconds. One advantage arising from this short exposure time was that a number of exposures of the same blot could be produced in a matter of minutes rather than many days as was the case with ${ }^{125} \mathrm{I}$ autoradiography. Blots could also be washed and stored for repeat ECL processing at a later date if necessary. The processing of the blots using roller mixing ${ }^{16}$ resulted in very economical use of antisera; about one tenth 
or less of the volumes required for conventional methods using plastic bags or trays were used.

In summary, the method described here is simple to carry out, uses minimal amounts of reagents, produces results within 48 hours, and does not require the use of potentially hazardous radioactive materials or carcinogenic enzyme substrates.

1 Ruggeri ZM, Zimmerman TS. Von Willebrand factor and von Willebrand disease. Blood 1987;70:895-904.

2 Rodeghiero F, Castaman G, Dini E. Epidemiological investigation of the prevalence of von Willebrand's disease. Blood 1987;69:454-9.

3 Miller $\mathbf{C H}$, Lenzi $\mathbf{R}$, Breen C. Prevalence of von Willebrand's disease among U.S. adults. Blood 1987; 70:377a.

4 Ruggeri ZM, Zimmerman TS. Variant von Willebrand's disease. Characterisation of two sub-types by analysis of multimeric composition of factor VIII/von Willebrand factor in plasma and platelets. $\mathcal{f}$ Clin Invest 1980; 65:1318-25.

5 Hoyer LW, Shainoff JR. Factor VIII-related protein circulates in normal human plasma as high molecular weight multimers. Blood 1980;55:1056-9.

6 Ruggeri ZM, Zimmerman TS. The complex multimeric composition of factor VIII/von Willebrand factor. Blood 1981;57:1140-3.

7 Furlong BL, Peake IR. An electroblotting technique for the detection of factor VIII/von Willebrand factor multimers in plasma. Br ₹ Haematol 1983;53:641-53.

8 Enayat MS, Hill FGH. Analysis of the complexity of the multimeric structure of factor VIII related antigen/von
Willebrand factor protein using a modified electrophoretic technique. $\mathcal{F}$ Clin Pathol 1983;36:915-9.

9 Miller MA, Palascak JE, Thompson MR, Martelo OJ. A modified SDS agarose gel method for determining factor VIII von Willebrand factor multimers using commercially available reagents. Thromb Res 1985;39: 777-80.

10 Lombardi R, Gelfi C, Righetti PG, Lattuada A, Mannucci PM. Electroblot and immunoperoxidase staining for rapid screening of the abnormalities of the multimeric structure of von Willebrand factor in von Willebrand's structure of von Willebrand factor in von
disease. Thromb Haemostas 1986;55:246-9.

11 Aihara M, Sawada Y, Ueno K, et al. Visualisation of von Willebrand factor multimers by immunoenzymatic stain
using avidin-biotin peroxidase complex. Thromb using avidin-biotin pera

12 Brosstad F, Kjonniksen I, Ronning B, Stormorken H. Visualisation of von Willebrand factor multimers by enzyme-conjugated secondary antibodies. Thromb Haemostas 1986;55:276-8.

13 Dalton RG, Lasham A, Savidge GF. A new rapid semidry blotting technique for multimeric sizing of von Willebrand factor. Thromb Res 1988;50:345-9.

14 Tomita Y, Harrison J, Abildgaard CF. Von Willebrand factor multimer analysis using a sensitive peroxidase staining method. Thromb Haemostas 1989;62:781-3.

15 Weiss HJ, Pietu G, Rabinowitz R, Girma J-P, Rogers J, Meyer D. Heterogeneous abnormalities in the multimeric structure, antigenic properties, and plasmameric structure, antigenic properties, and plasma-
platelet content of factor VIII/von Willebrand factor in platelet content of factor VII/von Willebrand factor in subtypes of classic (type I) and variant (type IIA) von
Willebrand's disease. $₹$ Lab Clin Med 1983;101:411-25.

16 Thomas N, Jones CN, Thomas PL. Low volume processing of protein blots in rolling drums. Anal Biochem 1988;170:393-6.

17 Schneppenheim R, Plendl H, Budde U. Luminographyan alternative assay for detection of von Willebrand factor multimers. Thromb Haemostas 1988;60:133-6.

18 Budde U, Schneppenheim R, Plendl H, Dent J, Ruggeri ZM, Zimmerman TS. Luminographic detection of von Willebrand factor multimers in agarose gels and on
nitrocellulose membranes. Thromb Haemostas 1990;63: 312-5. 